\title{
Calcium carbonate as ikaite crystals in Antarctic sea ice
}

\author{
Gerhard S. Dieckmann, ${ }^{1}$ Gernot Nehrke, ${ }^{1,2}$ Stathys Papadimitriou, ${ }^{3}$ Jörg Göttlicher, ${ }^{4}$ \\ Ralph Steininger, ${ }^{4}$ Hilary Kennedy, ${ }^{3}$ Dieter Wolf-Gladrow, ${ }^{1}$ and David N. Thomas ${ }^{3}$ \\ Received 5 February 2008; revised 9 March 2008; accepted 12 March 2008; published 18 April 2008.
}

[1] We report on the discovery of the mineral ikaite $\left(\mathrm{CaCO}_{3} \cdot 6 \mathrm{H}_{2} \mathrm{O}\right)$ in sea-ice from the Southern Ocean. The precipitation of $\mathrm{CaCO}_{3}$ during the freezing of seawater has previously been predicted from thermodynamic modelling, indirect measurements, and has been documented in artificial sea ice during laboratory experiments but has not been reported for natural sea-ice. It is assumed that $\mathrm{CaCO}_{3}$ formation in sea ice may be important for a sea ice-driven carbon pump in ice-covered oceanic waters. Without direct evidence of $\mathrm{CaCO}_{3}$ precipitation in sea ice, its role in this and other processes has remained speculative. The discovery of $\mathrm{CaCO}_{3} \cdot 6 \mathrm{H}_{2} \mathrm{O}$ crystals in natural sea ice provides the necessary evidence for the evaluation of previous assumptions and lays the foundation for further studies to help elucidate the role of ikaite in the carbon cycle of the seasonally sea icecovered regions. Citation: Dieckmann, G. S., G. Nehrke, S. Papadimitriou, J. Göttlicher, R. Steininger, H. Kennedy, D. WolfGladrow, and D. N. Thomas (2008), Calcium carbonate as ikaite crystals in Antarctic sea ice, Geophys. Res. Lett., 35, L08501, doi:10.1029/2008GL033540.

\section{Introduction}

[2] When sea ice forms, the hyper-saline brine generated within the ice matrix at sub-zero temperatures undergoes substantial changes with respect to mineral-liquid thermodynamic equilibria in the large spatial and temporal salinity and temperature spectra of the sea ice system. These physicochemical changes are conducive to sequential mineral precipitation [Marion, 2001]. Ikaite has been identified in a number of low temperature marine and saline terrestrial environments [e.g., Buchardt et al., 1997] and is thermodynamically viable in sea ice brine at equilibrium with current atmospheric $\mathrm{CO}_{2}$ at $-4.5^{\circ} \mathrm{C}$, in the absence of the formation of the anhydrous $\mathrm{CaCO}_{3}$ minerals. However, although precipitation of calcium carbonate $\left(\mathrm{CaCO}_{3}\right)$ in sea ice has been proposed for more than 50 years [Assur, 1958], actual evidence of its formation in sea ice has so far only been indirect [Killawee et al., 1998; Papadimitriou et al., 2004; Tison et al., 2002]. Not only has the question as to whether $\mathrm{CaCO}_{3}$ precipitates in natural sea ice remained unresolved, but also the polymorph of $\mathrm{CaCO}_{3}$ that would precipitate has

\footnotetext{
${ }^{1}$ Alfred-Wegener-Institute for Polar and Marine Research, Bremerhaven, Germany.

${ }^{2}$ Also at Geochemistry, Department of Earth Sciences, Faculty of Geosciences, Utrecht University, Utrecht, Netherlands.

${ }^{3}$ Ocean Sciences, College of Natural Sciences, University of WalesBangor, Menai Bridge, UK.

${ }^{4}$ Institute of Synchrotron Radiation (ISS), Synchrotron Radiation Source ANKA Forschungszentrum Karlsruhe, Eggenstein-Leopoldshafen, Germany.
}

Copyright 2008 by the American Geophysical Union. 0094-8276/08/2008GL033540\$05.00 been controversially discussed, e.g., thermodynamic calculations have been used that predict calcite to be the most likely precipitate in natural sea ice [Marion, 2001]. We first observed $\mathrm{CaCO}_{3}$ crystals in sea ice off Adelie Land, Antarctica in 2001 [see Delille et al., 2007]. Some of the crystals had the typical hexagonal and idiomorphic shape of the mineral ikaite $\left(\mathrm{CaCO}_{2} \cdot 6 \mathrm{H}_{2} \mathrm{O}\right)$. However, the crystals could not be investigated further because of incorrect handling. Ikaite is not stable at temperatures above $4^{\circ} \mathrm{C}$ and mineralogical phase identification requires that the crystals are processed, transported, and measured in a cryogenic environment. Thus, in order to correctly identify and quantify crystals from Antarctic sea ice, we again analysed ice cores collected from sea ice in the Weddell Sea, Antarctica during an expedition with the German research icebreaker Polarstern in austral spring (September-October) 2006.

\section{Methods}

[3] Sea ice cores where taken on different locations in the Weddell Sea, Antarctica between $60^{\circ}$ and $66^{\circ}$ south and $50^{\circ}$ and $58^{\circ}$ west. The cores represent different sea ice types, from $25 \mathrm{~cm}$ thick Nilas ice to $225 \mathrm{~cm}$ thick multi-year ice. Collection and processing of ice cores in the field proceeded with standard techniques [Horner et al., 1992]. Crystals were extracted from the ice cores as described below for (1) mineralogical phase identification and (2) quantitative determination of the crystals in the ice. In order to avoid decomposition of the crystals, the temperature throughout the sample preparation was maintained below $4^{\circ} \mathrm{C}$.

[4] Ice cores were cut into $10 \mathrm{~cm}$ segments, which were transferred into clean plastic containers, sealed and melted on board ship in a cold room at $4^{\circ} \mathrm{C}$ for two days. The melting was monitored several times a day and as soon as the sections had melted, processed within 2 minutes. Temperature of the melt water thus never rose much above $0^{\circ} \mathrm{C}$. After swirling the melt water and allowing particles to settle in the vortex, crystals were pipetted into a plastic vial containing $75 \%$ Ethanol and frozen at $-18^{\circ} \mathrm{C}$ for later mineralogical phase identification, or onto pre-weighed $\mathrm{GF} / \mathrm{F}$ filters for quantitative measurements. Filters were, rinsed with $75 \%$ ethanol, and kept frozen at $-18^{\circ} \mathrm{C}$. Before crystals were transferred they were briefly inspected under the binocular microscope to check for differences in morphology. Crystals for mineralogical phase identification were obtained from pooled triplicate sea ice cores of the top $30 \mathrm{~cm}$ of sea ice, from 13 stations. For comparison, $10 \mathrm{~cm}$ sections were cut from of an archive core (companion ice cores taken at each station and returned to the home laboratory in plastic tubes, at $-18^{\circ} \mathrm{C}$ ) and processed in a temperature controlled room $\left(\mathrm{T} \sim 2^{\circ} \mathrm{C}\right)$ as described for ship board samples. Analyses were done by means of X-ray diffraction using synchrotron radiation (X-ray beamline of 


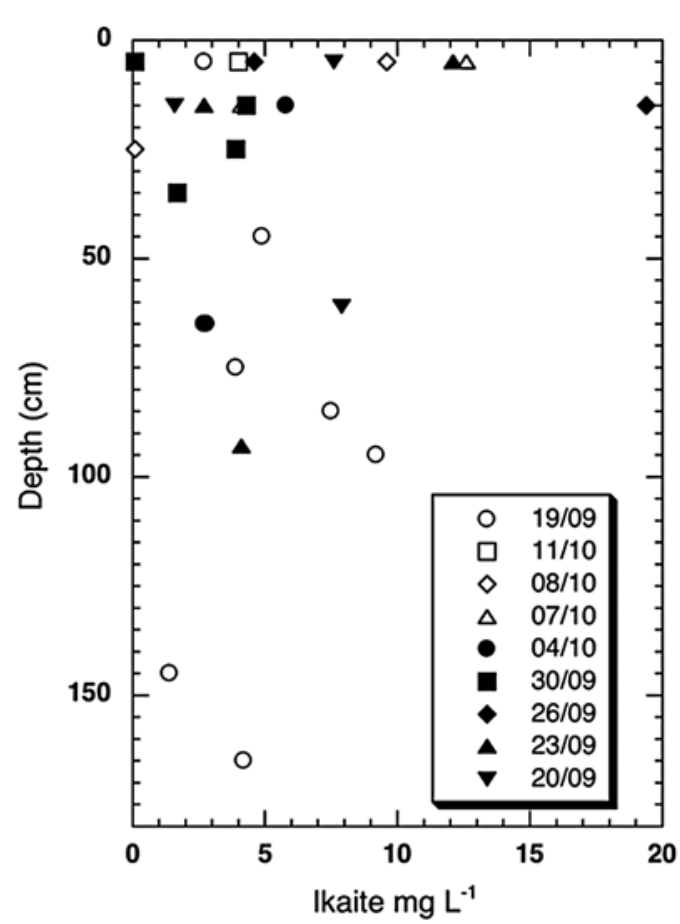

Figure 1. Distribution of the concentration of ikaite mass with depth in sea ice. Numbers in legend denote day/month of collection in 2006 (the ice-snow interface is assigned to $\mathrm{x}=0)$.

the Synchrotron Laboratory for Environmental Studies SUL-X at the synchrotron radiation source ANKA, Forschungszentrum Karlsruhe). Ikaite crystals were precipitated as reference material according to Marland [1975], $24 \mathrm{~h}$ before analysis. During transport to the synchrotron, samples were kept at a temperature below $2^{\circ} \mathrm{C}$. Diffracted intensities were collected from crystals that were either crushed and filled into glass capillaries or mounted on glass fibres in a cryogenic $\mathrm{N}_{2}$ gas stream with a focussed (150 $\mu \mathrm{m} \mathrm{x}$ $150 \mu \mathrm{m})$ monochromatic X-ray beam $(14 \mathrm{keV})$, using a CCD detector with a fibre-optic taper in the unbinned mode

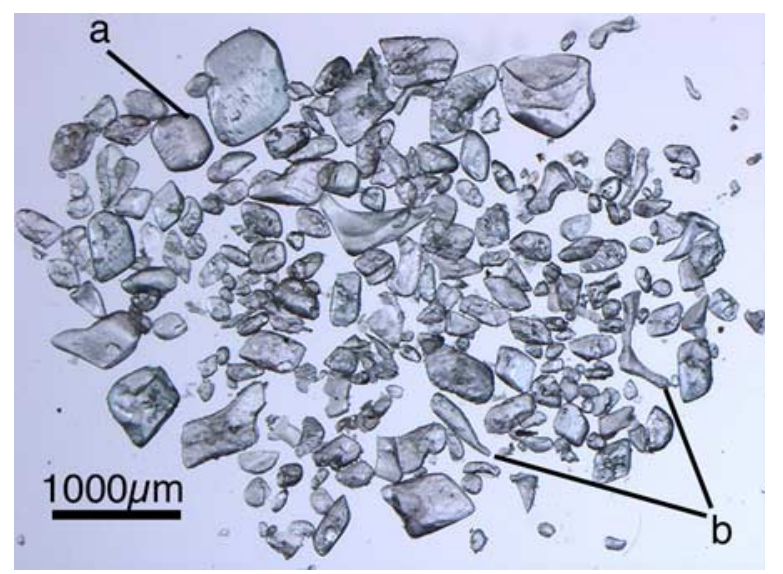

Figure 2. Photograph of ikaite crystals taken from a single bulk sea ice sample showing various crystal shapes and sizes: a, idiomorphic; and b, shape of brine pockets or channels.
(31.2 $\mu \mathrm{m}$ optical pixel size; type XDI-VHR, Photonic Science). Diffraction angles were calibrated with silicon and integrated to one dimensional background corrected powder diffractograms [Diffrac Plus Evaluation Package (1996-2001) Socabim; FIT2D, Hammerslay A. (19872005) ESRF].

[5] Quantification of crystals within sea ice was done using cores taken on 9 of the 13 stations. Filters prepared on board ship where dried in an oven at $60^{\circ} \mathrm{C}$ for 10 hours and weighed in the home laboratory. Because of the thermal instability of ikaite, the mineral mass thus quantified was

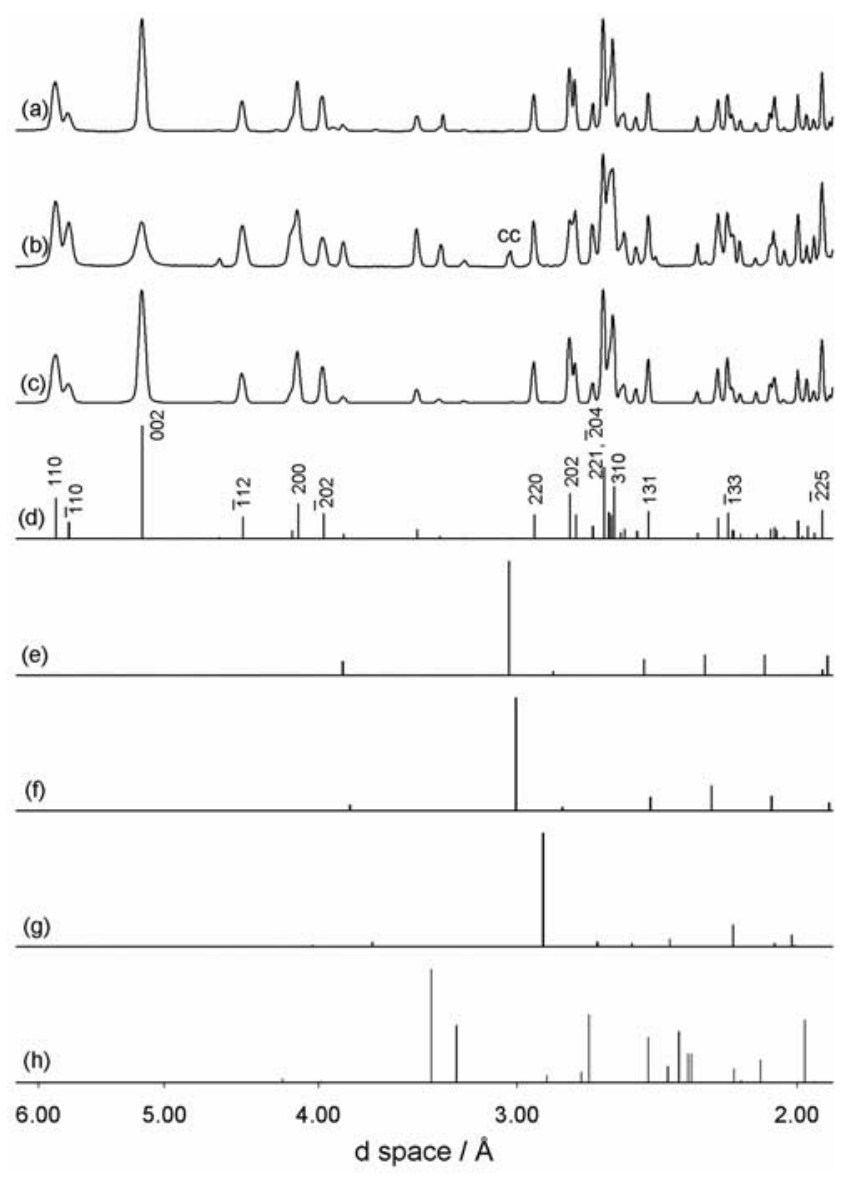

Figure 3. Synchrotron X-ray diffraction patterns (lattice spacing $d$ vs. diffracted intensity, strongest peak normalized to 1000 , intensity scales shifted for clarity) of (a) crystals isolated from an archived sea ice core in the home laboratory, (b) crystals isolated in the onboard laboratory and stored in $75 \%$ ethanol, (c) synthetic ikaite, and (d) line pattern with hkl reflections (JCPDS data base 75-1733, JCPD-International Centre for Diffraction Data (1999) PCPDFWIN v. 2.02.) from structure refinement data of ikaite from sea sediments in Bransfield Strait, Antarctica [Suess et al.,1982; Hesse et al., 1983]. Small amounts of calcite (cc) were detected in Figure 3b, probably from decomposition of ikaite. Line patterns for (e) calcite $\left(\mathrm{CaCO}_{3}\right)$, (f) calcite magnesium, $(\mathrm{g})$ dolomite $\left((\mathrm{Ca}, \mathrm{Mg}) \mathrm{CO}_{3}\right)$, and $(\mathrm{h})$ aragonite $\left(\mathrm{CaCO}_{3}\right)$ from the JCPDS database are added for comparison. The database numbers from Figures $3 \mathrm{e}-3 \mathrm{~h}$ are 00-005-0586, 00-043-0697, 00-0360426, and 00-041-1475. 
attributed to anhydrous $\mathrm{CaCO}_{3}$ and was converted to ikaite mass per liter of melted sea ice by multiplying with a factor of 2.08 (mineral molecular weight ratio). The area-weighted mineral mass was calculated from the sum of mineral mass isolated per core (corer ID $=9 \mathrm{~cm})$.

\section{Results and Discussion}

[6] Since all crystals extracted from the ice cores had the same morphology, it is most likely that the XRD identification as ikaite is representative for all crystals used in this study. Ikaite crystals were found throughout the sea ice and in all ice types but were not distributed uniformly with depth in the ice cores and up to $19.4 \mathrm{mg}$ of ikaite were found per liter of melted sea ice (Figure 1). The size of the ikaite crystals ranged from $<5 \mu \mathrm{m}$ to $600 \mu \mathrm{m}$, and their shape varied from almost idiomorphic (well developed crystal faces) to xenomorphic (no distinguishable crystal faces) (Figure 2). In some, the crystal shape was apparently constrained by the dimensions of the brine pockets in the ice. The discovery of ikaite crystals clearly indicates that the brine of the sampled sea ice was supersaturated with respect to ikaite, and that the formation of less soluble phases, e.g., calcite, aragonite or vaterite, appears to be kinetically inhibited. The total area-weighted mass of ikaite recovered from the cores ranged from 0.3 to $3.0 \mathrm{~g} \mathrm{~m}^{-2}$.

[7] Synchrotron X-ray diffraction patterns confirmed that the crystals were ikaite (Figure 3 ). The sequence of the $\mathrm{X}$ ray reflections of the field samples matches that of the synthetic ikaite prepared in the laboratory and the calculated line pattern of ikaite.

[8] The significance of ikaite authigenesis in sea ice on processes of global relevance can as yet not be fully assessed. At this point, little is known on the spatial and temporal occurrence of ikaite precipitates in polar sea-ice, but our subsequent discovery of crystals throughout fast ice off Adelie Land, Antarctica, in November 2007, morphologically identical to those from the north-western Weddell Sea, indicates that ikaite formation in sea ice is not a localized phenomenon. In sea ice, calcite or vaterite appear to be kinetically inhibited. A comparable environmental setting must be present in Antarctic sediments where ikaite is also found [Suess et al., 1982; Domack et al., 2007], although an exact understanding of the physio-chemical properties conducive to ikaite precipitation remains elusive. For sea ice, this knowledge is crucial since the precipitation of $\mathrm{CaCO}_{3}$ is implicated in many processes of global significance, such as the sea ice-driven carbon pump and the global carbon cycle [Delille et al., 2007; Rysgaard et al., 2007] with possible implications even for tropospheric ozone concentrations since calcium carbonate $\left(\mathrm{CaCO}_{3}\right)$ precipitation is thought to reduce the buffering capacity of sea ice brine, thus facilitating its acidification and triggering the bromine explosion considered responsible for the catalytic destruction of ozone [Sander et al., 2006].
[9] Acknowledgments. We thank Harald Zöller, Thomas Spangenberg, Michael Wünsch, and Karlheinze Cerff (all at Forschungszentrum Karslruhe) for technical and computing support before and during the measurements, as well as Christiane Uhlig for preparing the samples for minerology and synthetic ikaite and photography. The work was in part supported by the German Research Foundation (DFG) and is part of Project BI 432/3-2. It was also supported by the DFG under grants BI 432/3-2, BI 432/4-2 ('PaleoSalt'), and BI 432/6-1 ('BioCalc') and by the European Science Foundation (ESF) under the EUROCORES Programmes EuroCLIMATE and EuroMinScI, through contract ERAS-CT-2003-980409 of the European Commission, DG Research, FP6.

\section{References}

Assur, A. (1958), Composition of sea ice and its tensile strength, in Arctic Sea Ice Conference Proceedings, NAS-NCR Publ. 598, pp. 106-138, Natl. Acad. of Sci., Washington, D. C.

Buchardt, B., P. Seaman, G. Stockmann, M. Vous, U. Wilken, L. Duwel, A. Kristiansen, C. Jenner, and L. Thorbjorn (1997), Submarine columns of ikaite tufa, Nature, 390, 129-130.

Delille, B., B. Jourdain, A. V. Borges, J.-L. Tison, and D. Delille (2007), Biogas $\left(\mathrm{CO}_{2}, \mathrm{O}_{2}\right.$, dimethylsulfide) dynamics in spring Antarctic fast ice, Limnol. Oceanogr., 52, 1367-1379.

Domack, E. W., G. Halverson, V. Willmott, A. Leventer, S. Brachfeld, and S. Ishman (2007), Spatial and temporal distribution of ikaite crystals in Antarctic glacial marine sediments, edited by A. K. Cooper et al., U.S Geol. Surv. Open File Rep., 2007-1047.

Hesse, K. F., H. Kueppers, and E. Suess (1983), Refinement of the structure of Ikaite, $\left(\mathrm{CaCO}_{3} \cdot 6 \mathrm{H}_{2} \mathrm{O}\right)$, Z. Kristallogr., 163, 227-231.

Horner, R., S. F. Ackley, G. S. Dieckmann, B. Gulliksen, T. Hoshiai, L. Legendre, I. A. Melnikov, W. S. Reeburgh, M. Spindler, and C. W. Sullivan (1992), Ecology of sea ice biota 1. Habitat, terminology, and methodology, Polar Biol., 12, 417-427.

Killawee, J. A., I. J. Fairchild, J.-L. Tison, L. Janssens, and R. Lorrain (1998), Segregation of solutes and gases in experimental freezing of dilute solutions: Implications for natural glacial systems, Geochim. Cosmochim. Acta, 62, 3637-3655.

Marion, G. M. (2001), Carbonate mineral solubility at low temperatures in the $\mathrm{Na}-\mathrm{K}-\mathrm{Mg}-\mathrm{Ca}-\mathrm{H}-\mathrm{Cl}-\mathrm{SO}_{4}-\mathrm{OH}-\mathrm{HCO}_{3}-\mathrm{CO}_{3}-\mathrm{CO}_{2}-\mathrm{H}_{2} \mathrm{O}$ system, Geochim. Cosmochim. Acta, 65, 1883-1896.

Marland, G. (1975), Stability of calcium carbonate hexahydrate (ikaite), Geochim. Cosmochim. Acta, 39, 83-91.

Papadimitriou, S., H. Kennedy, G. Kattner, G. S. Dieckmann, and D. N. Thomas (2004), Experimental evidence for carbonate precipitation and $\mathrm{CO}_{2}$ degassing during sea ice formation, Geochim. Cosmochim. Acta., $68,1749-1761$.

Rysgaard, S., R. N. Glud, M. K. Sejr, J. Bendtsen, and P. B. Christensen (2007), Inorganic carbon transport during sea ice growth and decay: A carbon pump in polar seas, J. Geophys. Res., 112, C03016, doi:10.1029/ 2006JC003572.

Sander, R., J. Burrows, and L. Kaleschke (2006), Carbonate precipitation in brine: A potential trigger for tropospheric ozone depletion events, Atmos. Chem. Phys., 6, 4653-4658.

Suess, E., W. Balzer, K.-F. Hesse, P. J. Müller, C. A. Ungerer, and G. Wefer (1982), Calcium carbonate hexahydrate from organic-rich sediments of the Arctic Shelf: Precursors of glendonites, Science, 216, 1128-1130.

Tison, J.-L., C. Haas, M. M. Gowing, S. Sleewaegen, and A. Bernard (2002), Tank study of physico-chemical controls on gas content and composition during growth of young sea ice, J. Glaciol., 48, 177-191.

G. S. Dieckmann, G. Nehrke, and D. Wolf-Gladrow, Alfred-WegenerInstitute for Polar and Marine Research, Am Handelshafen 12, D-27570 Bremerhaven, Germany. (gerhard.dieckmann@awi.de)

J. Göttlicher and R. Steininger, Institute of Synchrotron Radiation (ISS), Synchrotron Radiation Source ANKA Forschungszentrum Karlsruhe, Hermann-von-Helmholtz-Platz 1, D-76344 Eggenstein-Leopoldshafen, Germany.

H. Kennedy, S. Papadimitriou, and D. N. Thomas, Ocean Sciences, College of Natural Sciences, University of Wales-Bangor, Menai Bridge LL59 5AB, UK. 